\title{
Preparation and Stability of Microcapsule Wood Preservative from Neem Extract
}

\author{
Luchen Liu and Guoqi $\mathrm{Xu}$ *
}

Neem (Melia azedarach) extract has good antibacterial properties, but its bioactivities are easily decomposed. In order to protect the bioactivities of neem extract, melamine urea formaldehyde (MUF) was used as wall material to prepare a wood microcapsule preservative. The size and distribution of microcapsules after treatments at different temperatures were determined by microscopy. These observations showed that increases in temperature caused the microcapsule particles to become smaller and more evenly distributed. The stability of this preservative was studied by use of an environmental factors experiment (ultraviolet light, condensation, and water spray) and a decay test. The results indicated that the microcapsule preservative from neem extract was more stable than the neem extract preservative. The results indicated that the microcapsule preservative from neem extract showed acceptable environmental stability. The water spray resistance of microcapsule preservative from neem extract was the best.

Keywords: Wood preservatives; Neem extract; Microcapsule; Environmental stability

Contact information: College of Engineering and Technology, Northeast Forestry University, Harbin 150040 China; *Corresponding authors: xuguoqi_2004@126.com

\section{INTRODUCTION}

Wood protection has been used since the early days, when people used coatings (such as tung oil and tannin) to protect wood (Lotz and Hollaway 1988). Copper chromium arsenate (CCA), lindane, and sodium pentachlorophenate have been extensively used worldwide. However, due to the toxicity of these preservatives, they have been phased out (Aceto and Fedele 1994). Many companies have developed more environmentally friendly wood preservatives and have applied for patents. Some of these preservatives have been used in practice such as quaternary ammonium copper series (ACQ-C and ACQ-D), CuHDO (Dibis, which stands for copper N-cyclohexane diazene dioxide), and Triazle (Hayoz et al. 2003). However, these types of wood preservatives have problems with the improvement of the anti-corrosion treatment process and the recycling of waste disposal materials (Lebow et al. 2004; Freeman et al. 2005; Ung and Cooper 2005; Eller et al. 2018).

Plants produce many metabolic products with bacteriostatic effects in the face of environmental intrusion (Gould 1989; Swain 1997; Teng et al. 2018). Therefore, plant extracts can be used as active ingredients in wood preservatives (Singh and Singh 2012). Extracts from neem (Melia azedarach) have excellent resistance to insect and fungi (Islam et al. 2009). Melia azedarach contains bioactive compounds such as azadirachtin and quercetin. Extremely low concentrations of azadirachtin and quercetin can inhibit the growth of wood-decay fungi (Dhyani and Tripathi 2006, 2008). Although azadirachtin extracts have a strong antibacterial effect, they are sensitive to ultraviolet rays and temperature (Jarvis et al. 1998). This leads to the inactivation of azadirachtin when it is 
used as a wood preservative, which affects the service life of the wood treated by neem extracts.

Microencapsulation is a promising remedial technique for resolving and addressing the environmental issue of pesticides (Takei et al. 2008; Zhu et al. 2010); this technique has been used for formulation of fenitrothion and methomyl (Knowles 1998). Microencapsulation entraps liquid or solid molecules in a polymeric shell material. It is commonly applied in various fields such as pesticide and medicine (Gao and Qian 2010; Li et al. 2011; Scott et al. 2011). Due to the small size of microcosmic "channels" such as wood vessels and pits (Uphill et al. 2014), the size and diameter of microcapsule granules are important for applying microcapsule technology to wood preservation. When the diameter of the microcapsule is less than $20 \mu \mathrm{m}$, it can be pressurized into some species of wood by vacuum impregnation (Hayward et al. 2014). Larger microcapsules are effectively imported by increasing the porosity of wood through microwave expansion and other pretreatment technologies (He et al. 2014). The above research indicates that this technology has certain difficulties in the use of wood preservation. In this study, microcapsule pre-preservative solution was inserted into wood and then solidified into a capsule by controlling the temperature. The air-stability of the preservative was investigated through environmental simulation experiments of sunlight, dew, and rain.

\section{EXPERIMENTAL}

\section{Materials}

Neem (Azadirachta indica A. Juss) seeds were picked from different trees in September 2017 (Yuanmou County, Yi Autonomous Prefecture of Chuxiong, Yun Nan Province, China (East longitude 101 ${ }^{\circ} 35^{\prime}$ '06' - $102^{\circ}, 25^{\circ} 23^{\prime}-26^{\circ} 06^{\prime}$ north latitude)). The seeds were washed, dried, and crushed through a 20-mesh sieve. Sapwood samples were cut from fresh felled poplar (Populus ussuriensis Kom.) (Dongfanghong Forest Farm, Heilongjiang Province, China). The samples were prepared from a board milled to $20 \mathrm{~mm}(\mathrm{R}) \times 20 \mathrm{~mm}(\mathrm{~L}) \times 10 \mathrm{~mm}(\mathrm{~T})$. The chemical reagents used in the experiment were anhydrous ethanol, distilled water, and 50\% melamine modified urea formaldehyde resin (Research Institute of Wood Industry, Chinese Academy of Forestry).

\section{Preparation of Microcapsule Pre-preservatives}

The active ingredients of neem were extracted from seeds using the water-bath method. The extraction temperature was $50{ }^{\circ} \mathrm{C}$. $50 \%$ ethanol aqueous solution was used for the extraction. The extracted solvent to material ratio was $16: 1$ by volume. The extracted mixture was suction-filtered to obtain a filtrate. The filtrate was placed on a rotary evaporator to obtain an extract of the neem seed active ingredient. All mixtures were formulated to contain $10 \%$ neem extract and $10 \%$ MUF by weight. The mixture treatments were prepared using a 90-4 digital temperature-controlled magnetic stirrer (Shanghai Zhenjie experimental equipment co. LTD, Shanghai, China) at a temperature of $50{ }^{\circ} \mathrm{C}$, a stirring speed of $1200 \mathrm{r} / \mathrm{min}$, and a stirring time of $1 \mathrm{~h}$.

\section{Immersion Treatment of Wood Samples}

All wood samples were extracted with purified water to remove impurities. The samples were numbered and sterilized in an autoclave at $120{ }^{\circ} \mathrm{C}$ for $1 \mathrm{~h}$. The samples were conditioned to a constant mass at $103{ }^{\circ} \mathrm{C}$ in a dryer and weighed. The wood samples 
were submerged under a given treatment solution and held under a vacuum for $12 \mathrm{~h}$. The treatment solutions were a microcapsule pre-preservative solution, an extract of the neem seed solution, and an MUF solution. The wood samples were removed, the surface solidified liquid was erased, and the mass of the wood was weighed after drying so that the drug loading could be calculated.

\section{Process of Microcapsule Formed Inside Wood Samples}

The treated with microcapsule pre-preservative solution samples were placed in an oven and gradually heated. The heating process is shown in Table 1 . The control points for each temperature increased from $40{ }^{\circ} \mathrm{C}$ to 80 with a $10{ }^{\circ} \mathrm{C}$ interval. The heating time of the samples in each stage was $5 \mathrm{~h}$. After drying all of the samples (A, B, C, D, E) at $40{ }^{\circ} \mathrm{C}$ for $5 \mathrm{~h}$, a certain amount of samples (A) was taken out. The remaining samples $(\mathrm{B}, \mathrm{C}, \mathrm{D}, \mathrm{E})$ were dried in the next stage at $50{ }^{\circ} \mathrm{C}$ for $5 \mathrm{~h}$, and then some samples (B) were taken out. The remaining samples $(\mathrm{C}, \mathrm{D}, \mathrm{E})$ continued to be heated at $60{ }^{\circ} \mathrm{C}$ for $5 \mathrm{~h}$, and the previous steps were repeated. Finally, the final samples (E), at an initial temperature of $80{ }^{\circ} \mathrm{C}$, passed through each stage of heating. With the gradual rise in temperature, the microcapsules gradually formed inside the samples.

Table 1. The Heating Process

\begin{tabular}{|c|c|c|}
\hline Sample Groups & $\begin{array}{c}\text { Heating } \\
\text { Temperature }\end{array}$ & Heating Time \\
\hline ABCDE & $40^{\circ} \mathrm{C}$ & $5 \mathrm{~h}$ \\
\hline $\mathrm{BCDE}$ & $50^{\circ} \mathrm{C}$ & $5 \mathrm{~h}$ \\
\hline $\mathrm{CDE}$ & $60^{\circ} \mathrm{C}$ & $5 \mathrm{~h}$ \\
\hline $\mathrm{DE}$ & $70^{\circ} \mathrm{C}$ & $5 \mathrm{~h}$ \\
\hline $\mathrm{E}$ & $80^{\circ} \mathrm{C}$ & $5 \mathrm{~h}$ \\
\hline
\end{tabular}

\section{Morphology Observations of the Treated Wood Samples}

The treated samples were cut into small pieces $(8 \mathrm{~mm}(\mathrm{R}) \times 8 \mathrm{~mm}(\mathrm{~T}) \times 1 \mathrm{~mm}$ (L)). The small samples were sputter-coated with gold. The morphology was observed by scanning electron microscopy (SEM, Quanta 200, FEI Co., Hillsboro, OR, USA). The acceleration voltage was set to $10 \mathrm{kv}$ to $15 \mathrm{kv}$, the beam spot was 2 to 3 , and the working distance was $10 \mathrm{~mm}$.

\section{Environmental Factors Experimental Design}

To evaluate the environmental stability of microcapsule wood preservatives, accelerated ageing tests of the three different treated wood samples (Table 2) were performed in an ultraviolet aging test chamber using ultraviolet rays, condensation, and spray. A UV-A340 lamp and UV-B313 was used to simulate the UV portion of the solar spectrum. The spray and condensation of water was used to simulate rain and dew.

\section{Decay Resistance Test of the Treated Wood Samples before and after Accelerated Ageing Tests}

This test used the samples in Table 2. The samples taken before the accelerated ageing tests were treated as the control experiment. The wood samples were tested for resistance to wood-decay fungi using a Chinese standard method of testing wood preservatives (GB/T 13942.1 2009). The treated wood samples were conditioned to a 
constant mass at $50{ }^{\circ} \mathrm{C}$ in dryer and weighed. The treated wood samples were sterilized in an autoclave at $120{ }^{\circ} \mathrm{C}$ for $1 \mathrm{~h}$. The samples were cultured in a river sand sawdust medium with brown rot fungi (Gloeophyllum trabeum) for 12 weeks. After 12 weeks, the mycelium on the sample surfaces was scraped, conditioned to a constant mass at $103{ }^{\circ} \mathrm{C}$ in a dryer, and weighed. The mass loss rate of the treated samples under various accelerated aging tests was calculated.

Table 2. The Environmental Factors Experimental Design

\begin{tabular}{|c|c|c|c|}
\hline $\begin{array}{l}\text { Experiment } \\
\text { Types }\end{array}$ & $\begin{array}{l}\text { Processing } \\
\text { Conditions }\end{array}$ & $\begin{array}{l}\text { Processing } \\
\text { Time }\end{array}$ & Treating Solution \\
\hline \multirow{9}{*}{$\begin{array}{c}\text { Single-factor } \\
\text { test }\end{array}$} & \multirow{3}{*}{ Ultraviolet light } & $24 \mathrm{~h}$ & \multirow{3}{*}{$\begin{array}{c}\text { Neem seed extract } \\
\text { Microcapsule preservative } \\
\text { MUF }\end{array}$} \\
\hline & & $48 \mathrm{~h}$ & \\
\hline & & $72 \mathrm{~h}$ & \\
\hline & \multirow{3}{*}{ Condensation } & $24 \mathrm{~h}$ & \multirow{3}{*}{$\begin{array}{c}\text { Neem seed extract } \\
\text { Microcapsule preservative } \\
\text { MUF }\end{array}$} \\
\hline & & $48 \mathrm{~h}$ & \\
\hline & & $72 \mathrm{~h}$ & \\
\hline & \multirow{3}{*}{ Water spray } & $24 \mathrm{~h}$ & \multirow{3}{*}{$\begin{array}{c}\text { Neem seed extract } \\
\text { Microcapsule preservative } \\
\text { MUF }\end{array}$} \\
\hline & & $48 \mathrm{~h}$ & \\
\hline & & $72 \mathrm{~h}$ & \\
\hline \multirow{6}{*}{ Two-factor test } & \multirow{3}{*}{$\begin{array}{l}\text { Ultraviolet light+ } \\
\text { Condensation }\end{array}$} & $12 \mathrm{~h}+12 \mathrm{~h}$ & \multirow{3}{*}{$\begin{array}{c}\text { Neem seed extract } \\
\text { Microcapsule preservative } \\
\text { MUF }\end{array}$} \\
\hline & & $24 h+24 h$ & \\
\hline & & $36 h+36 h$ & \\
\hline & \multirow{3}{*}{$\begin{array}{c}\text { Ultraviolet } \\
\text { light+water spray }\end{array}$} & $12 \mathrm{~h}+12 \mathrm{~h}$ & \multirow{3}{*}{$\begin{array}{c}\text { Neem seed extract } \\
\text { Microcapsule preservative } \\
\text { MUF }\end{array}$} \\
\hline & & $24 h+24 h$ & \\
\hline & & $36 h+36 h$ & \\
\hline
\end{tabular}

\section{RESULTS AND DISCUSSION}

\section{Observation of the Morphology of the internal Microcapsule in Treated Wood Samples}

The morphology of the wood samples that did not undergo the soaking treatment is shown in Fig. 1. The SEM images show the morphologies of the internal microcapsules of the samples under different control temperatures after gradual heating (Figs. 2 to 6). Some tiny particles were visualized to have formed inside the treated wood samples. This indicated that a large number of microcapsules had been formed in the wood cavity after it was impregnated with the microcapsule pre-preservative solution and was heat cured. This kind of microcapsule structure used MUF as the wall material. The neem extracts were wrapped inside as core material and then fixed in the cavity of the samples. During the microcapsule process, the prepolymer condensed to form MUF particles in the aqueous solution, then the particles aggregated and were deposited at the surface of the internal phase (neem extracts). The morphologies of the internal microcapsules in the samples treated at temperatures below $40{ }^{\circ} \mathrm{C}$ are shown in Fig. 2, which shows that the microcapsule existed in some places of the samples, while it was not distributed in some other places. The distribution of the microcapsule was very uneven and sparse. The mean diameter of the microcapsules was slightly larger. The morphology of the internal microcapsule in the samples treated at temperatures below $50{ }^{\circ} \mathrm{C}$ are shown in Fig. 3 . 
Compared with the microstructure of wood treated below $40{ }^{\circ} \mathrm{C}$, the microcapsule distributions were more uniform, dense, and showed a trend of decreasing of particle size. The morphology of the internal microcapsule in the samples treated at temperatures below $60{ }^{\circ} \mathrm{C}$ are shown in Fig. 4. The size of microcapsules decreased and the distribution of microcapsules was more uniform than that of the samples taken under low temperature conditions. The morphology of the internal microcapsule in the treated wood samples under $70{ }^{\circ} \mathrm{C}$ are shown in Fig. 5, which indicates that tiny microcapsule particles in the cell wall of the wood gradually formed a microcapsule structure similar to the membrane shape. The microcapsule was attached to the inner wall of the wood pit. The morphology of the internal microcapsule in the samples treated at temperatures below 80 ${ }^{\circ} \mathrm{C}$ were shown in Fig. 6. It was shown that the particle size of the microcapsule further decreased and became more similar to the membrane structure. The average particle size of the microcapsule was about $1 \mu \mathrm{m}$. Microcapsules were also the most evenly distributed. Therefore, the temperature of the treatment affected the uniformity and particle size of encapsulation in the wood samples.

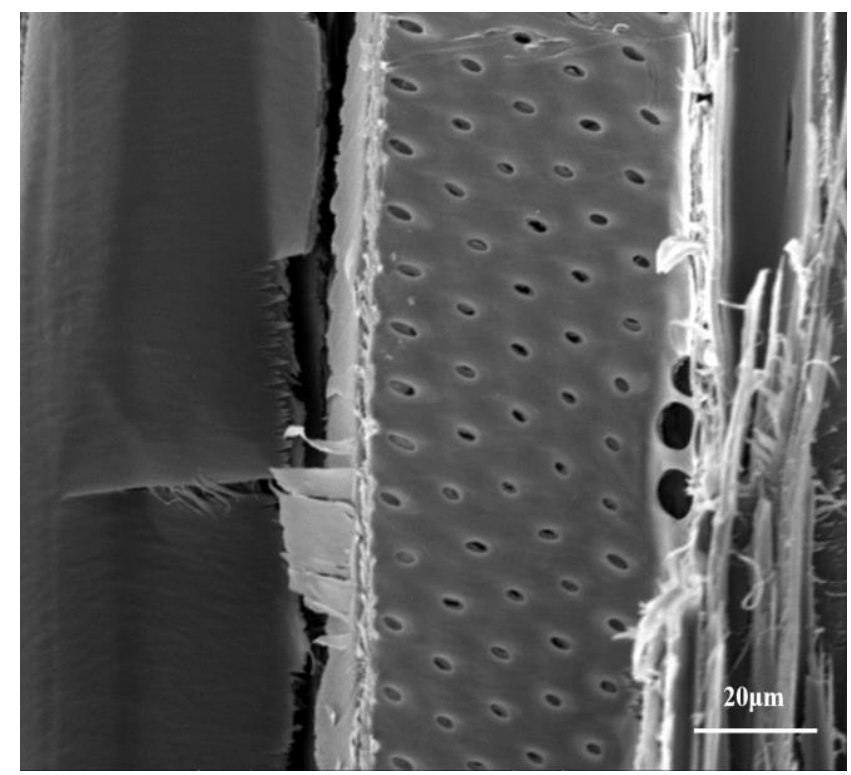

Fig. 1. The morphology of wood samples without soaking treatment
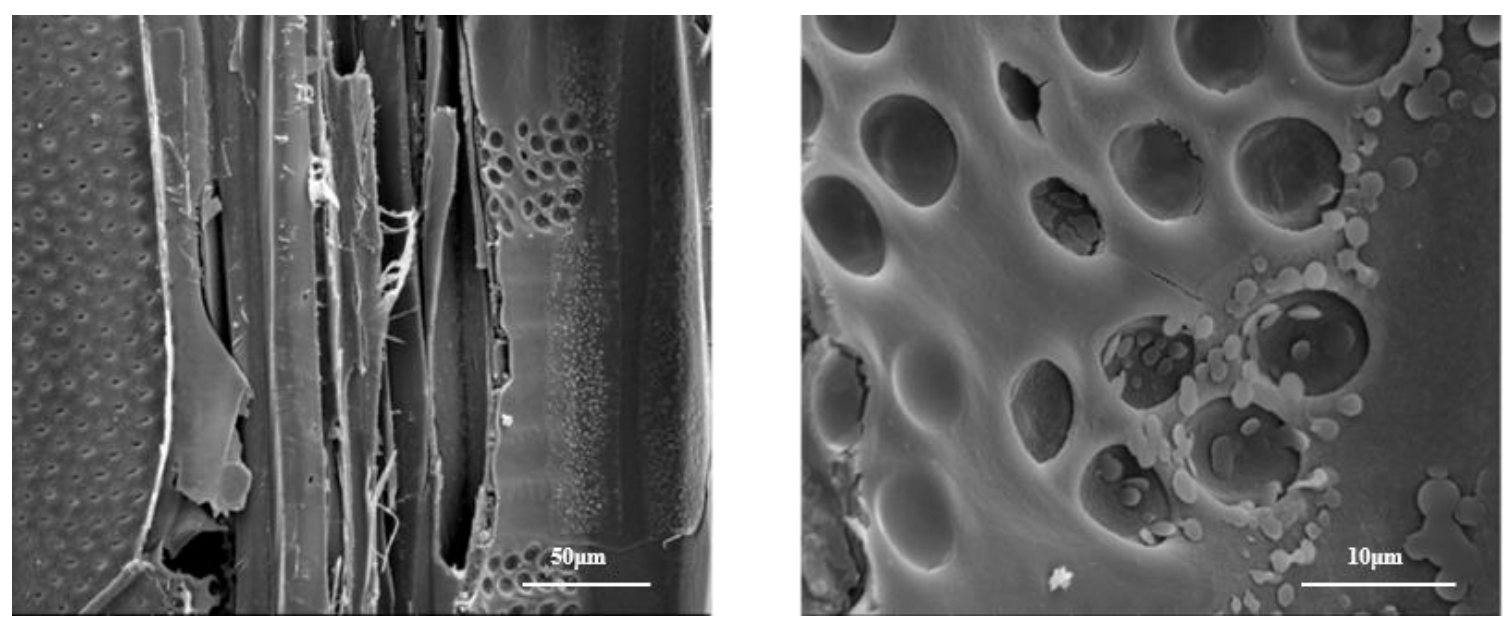

Fig. 2. The morphology of the internal microcapsule in treated samples under $40^{\circ} \mathrm{C}$ 

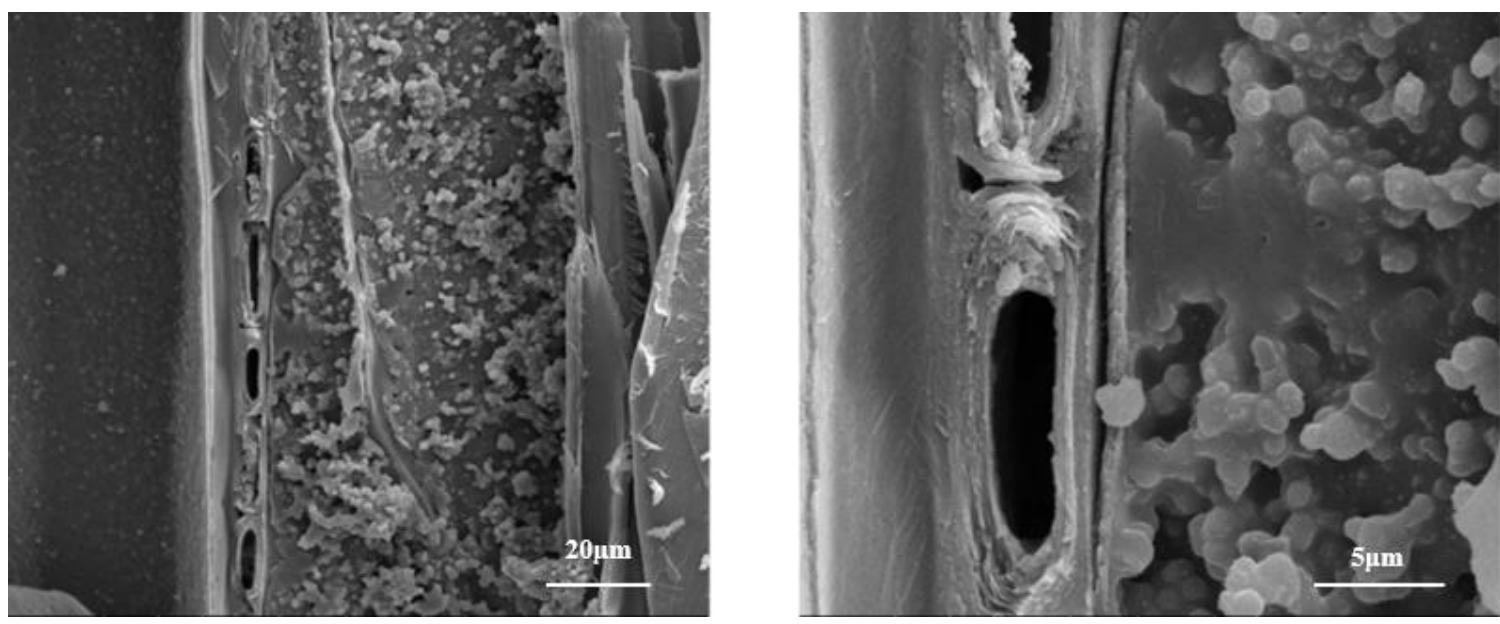

Fig. 3. The morphology of the internal microcapsule in treated samples under $50{ }^{\circ} \mathrm{C}$
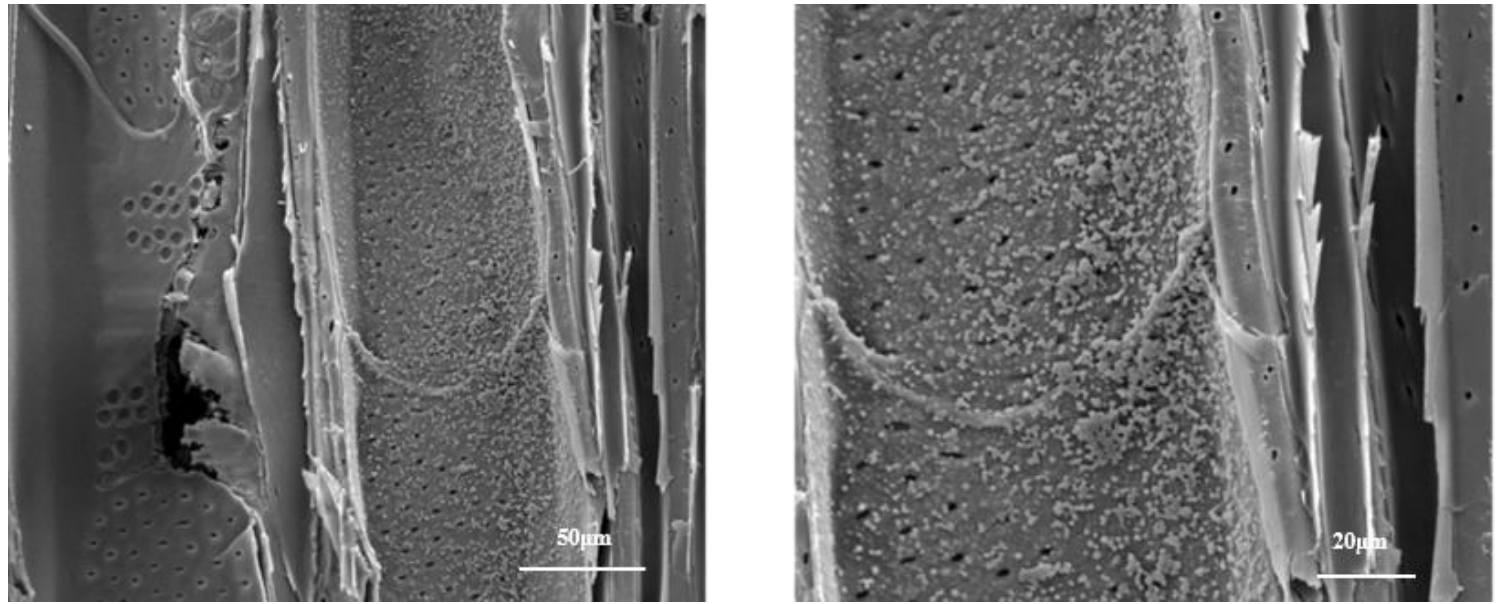

Fig. 4. The morphology of the internal microcapsule in treated samples under $60^{\circ} \mathrm{C}$
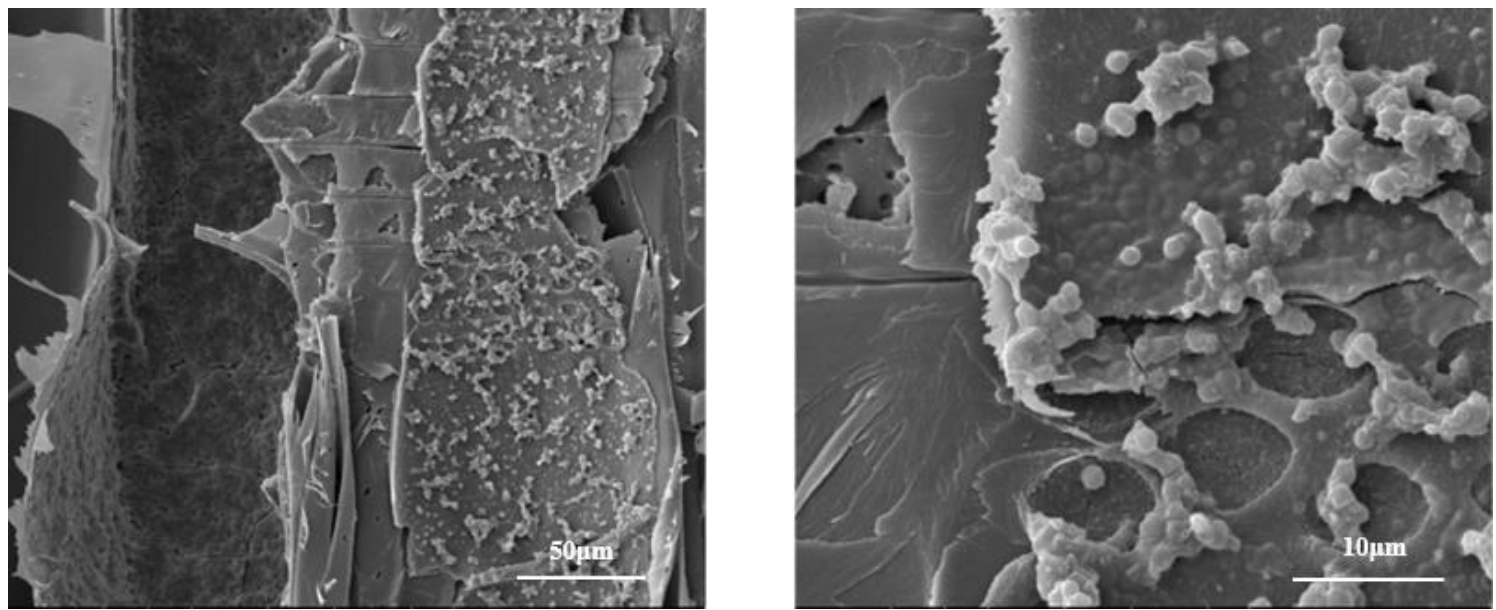

Fig. 5. The morphology of the internal microcapsule in treated samples under $70{ }^{\circ} \mathrm{C}$ 

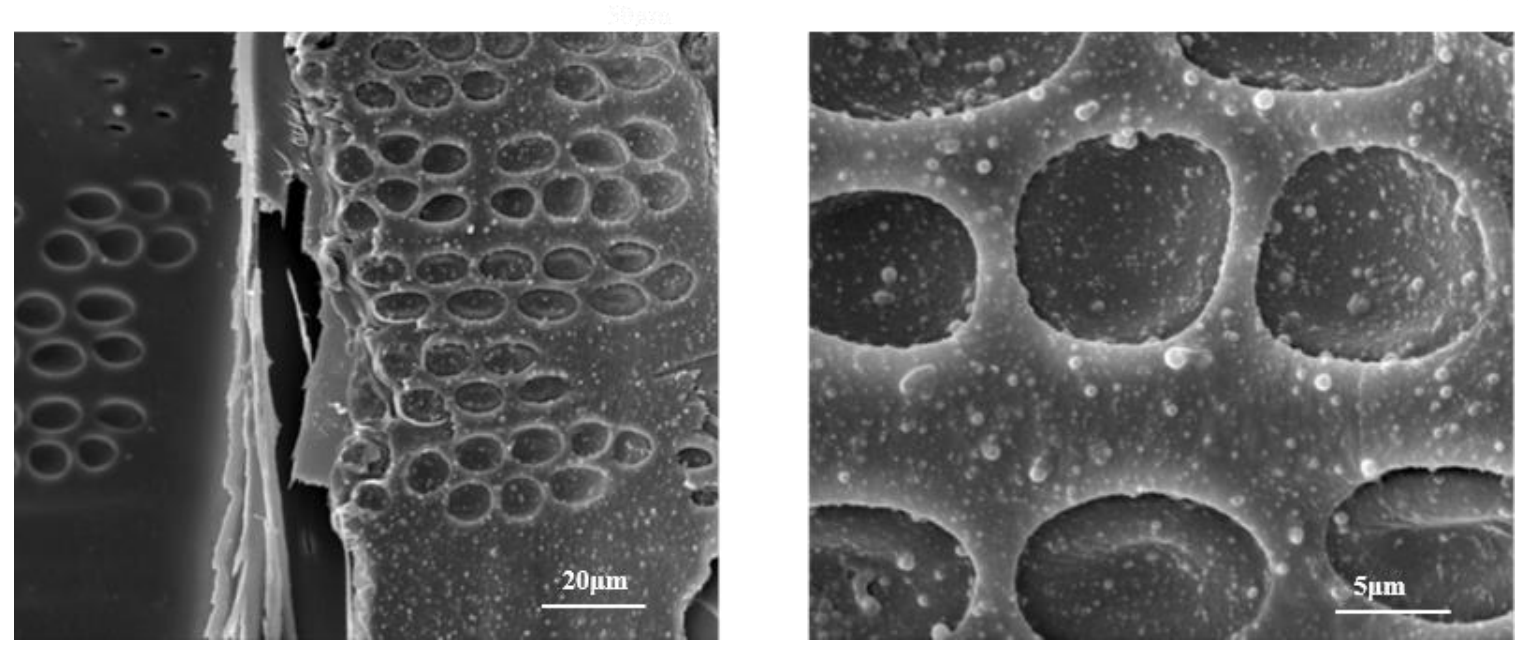

Fig. 6. The morphology of the internal microcapsule in treated samples under $80^{\circ} \mathrm{C}$

\section{Environmental Factors Experimental Analysis}

Control experiment analysis

The mass loss rates of the control samples attacked by brown rot fungi are shown in Table 3. The grading standards of decay resistance are shown in Table 4. The highest mass loss rate was found in the water-treated samples, and the lowest was the present in the microcapsule preservative-treated samples. The microcapsule preservative had the best decay resistance, followed by the neem extract, while MUF and water had little to no decay resistance. Thus, the antibacterial component was in the neem extract. After the neem extract was coated with MUF to form microcapsules, it could not decompose easily due to the protective effect of wall material, so the effect of the drug lasted longer.

Table 3. Decay Resistance of Control Group

\begin{tabular}{|c|c|c|c|}
\hline Treatment Solution & Concentration (By Weight) & Mass Loss Rate (\%) & Durability Class \\
\hline Neem extract & $10 \%$ & 12.35 & Durable \\
\hline $\begin{array}{c}\text { Microcapsule } \\
\text { preservative }\end{array}$ & $10 \%$ & 6.60 & Strong durable \\
\hline MUF & $10 \%$ & 46.11 & Non-durable \\
\hline Water & - & 54.81 & Non-durable \\
\hline
\end{tabular}

Table 4. Grading Standards of Decay Resistance

\begin{tabular}{|c|c|c|}
\hline Classes & Durability Class & Mass Loss Rate (\%) \\
\hline I & Strong durable & $0-10$ \\
\hline II & Durable & $11-24$ \\
\hline III & Less durable & $25-44$ \\
\hline IV & Non-durable & $>45$ \\
\hline
\end{tabular}

Environmental factors experimental analysis

The results of the resistance test for the brown fungi after single-factor test are shown in Fig. 7. The mass loss rate of the samples treated by microcapsule preservatives was the lowest in all conditions, followed by the mass loss rate of the samples treated by neem extract. The highest mass loss rate was displayed by the samples treated with MUF. 
The mass loss rate of the samples treated by microcapsule preservatives and exposed to UV and condensation increased with time. However, the mass loss rate of the samples treated by microcapsule preservatives and exposed to spray did not change with the increase of the treatment time. This result indicated that the microcapsules had the best resistance to spray.

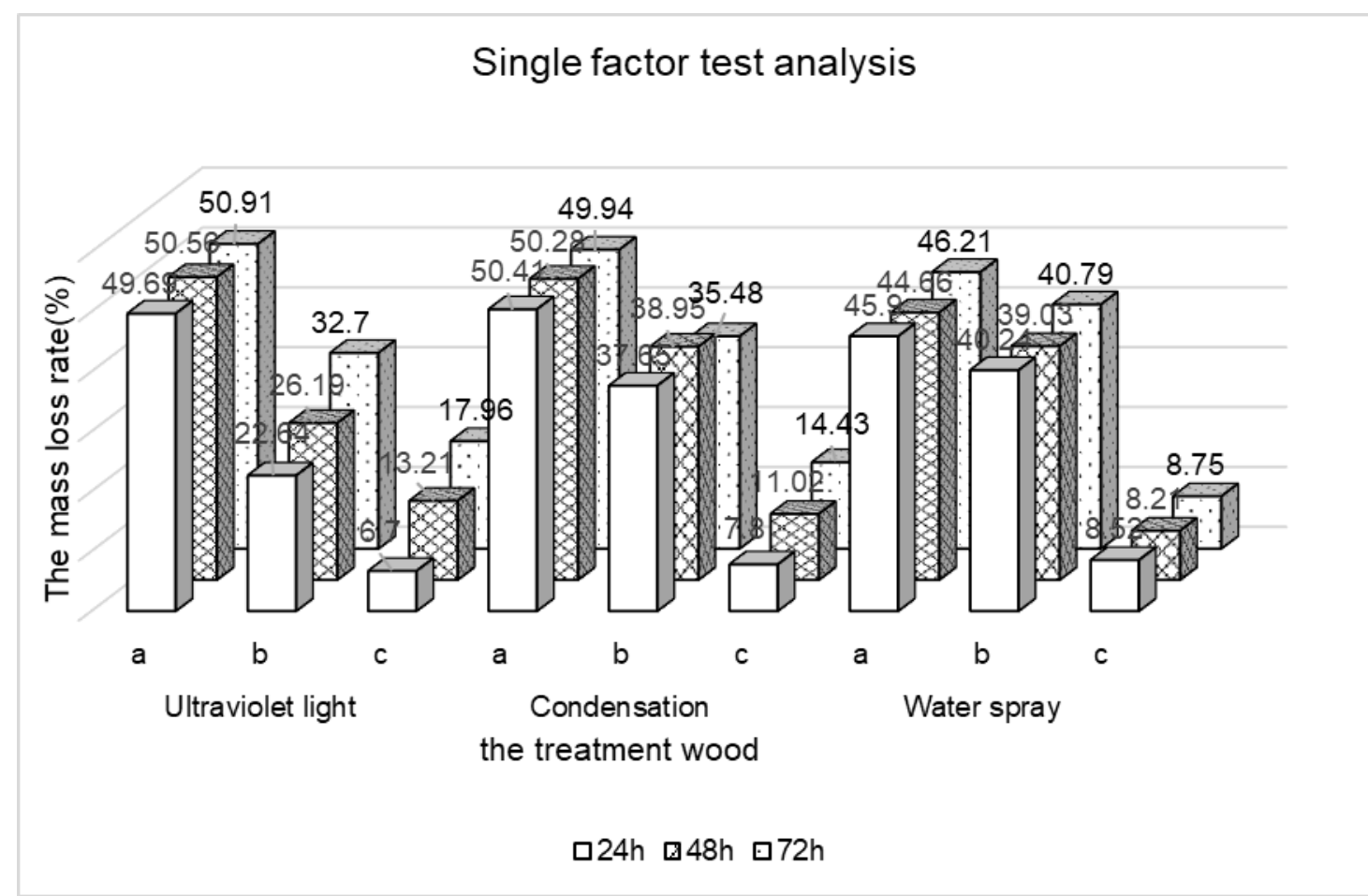

Fig. 7. The mass loss rate of the treated samples by single environmental factors was attacked by brown fungi (a: MUF, b: 10\% neem extract, c: 10\% microcapsule preservatives)

Compared with the mass loss rate of the samples before accelerated ageing tests (Table 3), the durability class of the samples treated by MUF did not change under any conditions. They were still at a non-durable level, which showed that the MUF did not have preservative properties. After $24 \mathrm{~h}$ of UV treatment, the durability class of the samples treated by neem extract remained unchanged. After $48 \mathrm{~h}$ of UV treatment, the durability class of the samples treated by neem extract went from a durable level to a less durable level. After $48 \mathrm{~h}$ of UV treatment, the durability class of the samples treated by neem extract was less durable. After $24 \mathrm{~h}$ of UV treatment, the durability class of the samples treated by microcapsule preservatives remained unchanged. However, after $48 \mathrm{~h}$ or $72 \mathrm{~h}$ of UV treatment, the durability class of the samples treated by microcapsule preservatives still remained at a durable level.

The above data indicated that UV in the environment could indeed influence the antibacterial component of neem extract. The antibacterial effect decreased with the increase of ultraviolet irradiation. After the microcapsule structure of the extract and MUF was formed in the samples, the influence of UV on the microcapsule was reduced and the antibacterial component of the extract was protected by MUF. So, the antibacterial effect of the extract was prolonged.

The effect of condensation treatment on neem extract was noticeable. After $24 \mathrm{~h}$ of condensation treatment, the durability class of the samples treated by neem extract 
remained unchanged. After $48 \mathrm{~h}$ of condensation treatment, the durability class of the samples treated by neem extract went from a durable level to a less durable level. After $48 \mathrm{~h}$ of condensation treatment, the durability class of the samples treated by neem extract was at a less durable level. After $24 \mathrm{~h}$ of condensation treatment, the durability class of the samples treated by microcapsule preservatives remained unchanged. However, after $48 \mathrm{~h}$ or $72 \mathrm{~h}$ of condensation treatment, the durability class of the samples treated by microcapsule preservatives still remained at a durable level. During the condensation treatment, water infiltrated the samples. The antibacterial component was lost with the water. The surface of the microcapsule preservative was protected by a layer of wall material (MUF), which made the microcapsule preservative more stabilized than neem extract.

The effect of the spraying treatment on the neem extract was most noticeable compared with the control group. After $24 \mathrm{~h}$ of spraying treatment, the durability class of the samples treated by neem extract went from a durable level to a less durable level. However, the durability class of the samples treated by microcapsule preservatives remained at a strong durable level for the duration of the study. This was because the spray simulated the washing effect of rainwater, so that the antibacterial components flowed out with the water flow, thus reducing the amounts of antibacterial components in the samples. However, the microcapsule preservative could resist the erosion effect of rainwater. This indicated that the prepared microcapsule preservative had a strong resistance to rainwater.

According to the above experiments, the environmental stability of neem extract was poor. The samples treated with neem extract had poor resistance to all three environmental simulations, which made the wood samples vulnerable to decay. Because the microcapsule preservatives were covered by a layer of wall material, the effect of three factors on extract was reduced, and the bacteriostatic effect of the extract was prolonged. The microcapsule preservatives had the best resistance to rainwater and could resist rain erosion for a long time. They also had better resistance to dew and sunlight for a short time. Therefore, the results showed the microcapsule preservatives could protect the antibacterial activity of neem extract by reducing the influence of the environment, which made the antibacterial effect release slowly, prolonging the preservative effect.

The results of the two-factor accelerated ageing tests are presented in Fig. 8. The decay resistance of the neem extract treated by a two factors test decreased greatly compared to a single factor experiment. Compared with the mass loss rate of the samples before accelerated ageing tests (Table 3), the durability class of the samples treated by neem extract went from a durable level to a non-durable level under any conditions. After any environmental treatment, the neem extract was no longer resistant to fungi decay, so it could not protect the wood. After exposure to UV and condensation, the durability class of the samples treated by microcapsule preservatives still remained at a durable level. After exposure to UV and spray, the durability class of the samples treated by microcapsule preservatives still remained at a durable level. This indicated that the microcapsule preservative extract had a certain resistance to the various environmental factors and could protect the wood from fungal decay to a certain extent. The decay resistance mechanism of the microcapsule preservatives and the slow-release properties of active ingredients will be further discussed in a subsequent study. This would help further the understanding of the service life of the microcapsule preservative and improve its performance in order to apply it in practice. 


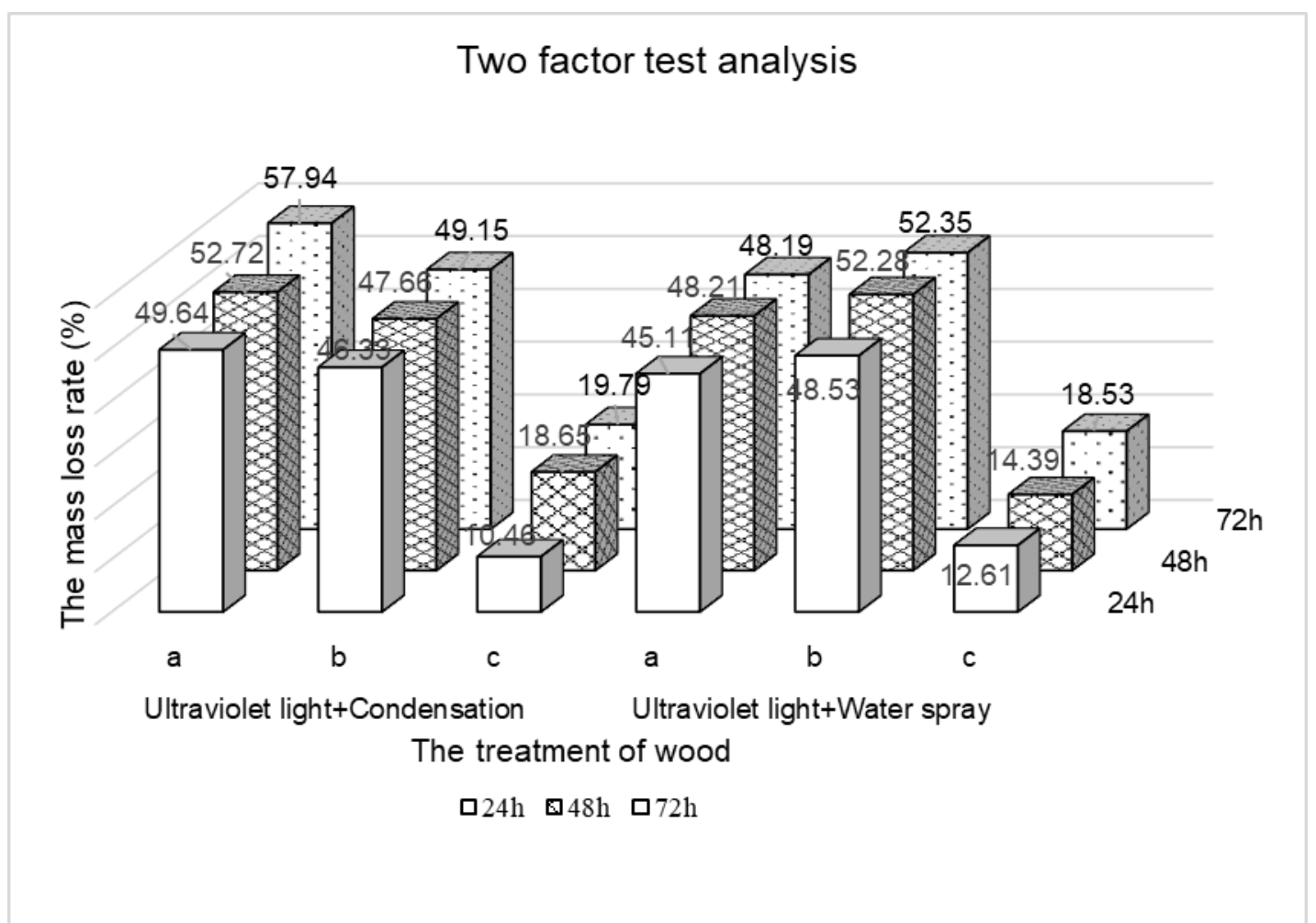

Fig. 8. The mass loss rate of the treated samples by two environmental factors was attacked by brown fungi (a: MUF, b: 10\% neem extract, c: 10\% microcapsule preservatives)

\section{CONCLUSIONS}

1. With increasing temperature, the diameter of the microcapsules within the wood specimens decreased gradually. The distribution in the wood cell wall was more uniform, and the binding was closer. The microcapsule preservative prepared by neem extracts experienced a slow release of its antibacterial properties when MUF was used as the coating of its wall material.

2. This research simulated the use of wood preservatives in outdoor environments, such as sunlight, dew, and rain. The stability of neem extract in microcapsule form was greatly improved. The neem extract microcapsule preservatives had certain resistance to sunlight, dew, rain, and effects of their interaction. The rain resistance of the neem extract microcapsule preservative was the best among the samples.

3. This study indicated that the microcapsule preservative had a certain prospect for application as an environmentally friendly wood preservative. Through the coating of the wall layer, the active ingredients of the plant extract could be protected inside of the microcapsule, reducing the volatility of the active ingredients. 


\section{ACKNOWLEDGEMENT}

This work was financially supported by the Natural Science Foundation of China (Grant No. 31500470), and the Natural Science Foundation of Heilongjiang Province, China (Grant No. C 2016014).

\section{REFERENCES CITED}

Aceto, M., and Fedele A. (1994). "Rain water effect on the release of arsenic, chromium and copper from treated wood," Fresenius Environ Bulletin 3(7), 389-394.

Dhyani, S., and Tripathi, S (2006). "Protection of hard and softwood through neem leaves extracts and oil: A direction towards development of eco-friendly wood preservatives," in: The 37th Annual Meeting of International Research Group on Wood Preservation, Troms $\varnothing$, Norway.

Dhyani, S., and Tripathi, S. (2008). "Quercetin-a potential compound of Azadirachta indica A. Juss. (neem) leaves exhibiting activity against wood decaying fungi and termites," in: Proceedings of the $39^{\text {th }}$ International Research Group on Wood Preservation, Istanbul, Turkey.

Eller, F. J., Hay, W. T., Kirker, G. T., Mankowski, M. E., and Selling, G. W. (2018). "Hexadecyl ammonium chloride amylose inclusion complex to emulsify cedarwood oil and treat wood against termites and wood-decay fungi," International Biodeterioration and Biodegradation 129, 95-101. DOI: 10.1016/j.ibiod.2018.01.010

Freeman, M. H., Nicholas, D. D., and Schultz, T. P. (2005). "Non-arsenical wood protection: alternatives for CCA, creosote, and pentaclorophenol," Environmental Impacts of Treated Wood, Chapter 2. DOI: 10.1201/9781420006216.ch2

Gao, G. B., and Qian, C. X. (2010). "Preparation and characterization of hexadecane microcapsule with polyurea-melamine formaldehyde resin shell materials," Chinese Chemical Letters 21(5), 533-537. DOI: 10.1016/j.cclet.2009.11.021

GB/T 13942.1 (2009). "Durability of wood - Part 1: Method for laboratory test of natural decay resistance," Standardization Administration of China, China.

Gould, G. W. (1989). Mechanisms of Action of Food Preservation Procedures, Springer, Berlin, Germany.

Hayoz, P., Peter, W., and Rogez, D. (2003). "A new innovative stabilization method for the protection of natural wood," Progress in Organic Coatings 48(2-4), 297-309. DOI: 10.1016/S0300-9440(03)00102-4

Hayward, P. J., Rae, W. J., and Black, J. M. (2014). “Encapsulated wood preservatives," U. S. Patent No. 20140057095A1.

He, S., Lin, L., Fu, F., Zhou, Y., and Fan, M. (2014). "Microwave treatment for enhancing the liquid permeability of Chinese fir," BioResources 9(2), 1924-1938. DOI: 10.15376/biores.9.2.1924-1938

Islam, M. M., Shams, M. I., Ilias, G. N. M., and Hannan, M. O. (2009). "Protective antifungal effect of neem (Azadirachta indica) extracts on mango (Mangifera indica) and rain tree (Albizia saman) wood," International Biodeterioration and Biodegradation 63(2), 241-243. DOI: 10.1016/j.ibiod.2008.07.010

Jarvis, A. P., Johnson, S., Morgan, E. D. (1998). "Stability of the natural insecticide azadirachtin in aqueous and organic solvents," Pest Management Science 53(3), 217 222. DOI: 10.1002/(SICI)1096-9063(199807)53:3<217::AID-PS766>3.0.CO;2-9 
Knowles, D. A. (1998). Chemistry and Technology of Agrochemical Formulations, Springer Netherlands, Heidelberg, Germany.

Li, J., Wang, S., Liu, H., Liu, N., and You, L. (2011). "Preparation and application of poly(melamine-urea-formaldehyde) microcapsules filled with sulfur," Polymer Plastics Technology and Engineering 50(7), 689-697. DOI: 10.1080/03602559.2010.551389

Lebow, S., Winandy, J., and Bender, D. (2004). "Treated wood in transition: A look at CCA and the candidates to replace it," Frame Building News 32-38.

Lotz, R. W., and Hollaway, D. F. (1988). "Wood preservation," U. S. Patent No. 4732817.

Scott, A. W., Tyler, B. M., Masi, B. C., Upadhyay, U. M., Patta, Y. R., Grossman, R., Basaldella, L., Langer, R. S., Brem, H., and Cima, M. J. (2011). "Intracranial microcapsule drug delivery device for the treatment of an experimental gliosarcoma model," Biomaterials 32(10), 2532-2539. DOI: 10.1016/j.biomaterials.2010.12.020

Swain, T. (1977). "Secondary compounds as protective agents," Annual Review of Plant Physiology 28(1), 479-501. DOI: 10.1146/annurev.pp.28.060177.002403

Takei, T., Yoshida, M., Yanagi, K., Hatate, Y., and Shiomori, K. (2008).

"Preparation of acetamiprid-loaded polymeric microcapsules: Influence of preparation parameter in emulsion, system on microcapsule characteristics," Polymer Bulletin 61(1), 119-127. DOI: 10.1007/s00289-008-0935-5

Teng, T.-J., Mat Arip, M. N., Sudesh, K., Nemoikina, A., Jalaludin, Z., Ng, E.-P., Lee, H.-L. (2018). Conventional technology and nanotechnology in wood preservation: A review," BioResources 13(4), 9220-9252. DOI: 10.15376/biores.13.4.9220-9252

Ung, Y. T., and Cooper, P. A. (2005). "Copper stabilization in ACQ-D treated wood: Retention, temperature and species effects," Holz als Roh- und Werkstoff 63(3), 186191. DOI: $10.1007 / \mathrm{s} 00107-004-0555-1$

Uphill, S. J., Cosgrove, T., and Briscoe, W. H. (2014). "Flow of nanofluids through porous media: Preserving timber with colloid science," Colloids and Surfaces A: Physicochemical and Engineering Aspects 460(9), 38-50. DOI:

10.1016/j.colsurfa.2014.05.008

Zhu, L., Wang, Z., Zhang, S., and Long, X. (2010). "Fast microencapsulation of chlorpyrifos and bioassay," Journal of Pesticide Science 35(2), 339-343. DOI: 10.1584/jpestics.G09-43

Article submitted: January 1, 2019; Peer review completed: February 24, 2019; revised version received and accepted: March 2, 2019; Published: March 6, 2019.

DOI: $10.15376 /$ biores. 14.2.3352-3363 